Cite this: Chem. Commun., 2014, 50, 100

Received 29th August 2013,

Accepted 8th October 2013

DOI: $10.1039 / c 3 c c 46629 a$

www.rsc.org/chemcomm

\title{
Shining light on integrity of a tetracobalt- polyoxometalate water oxidation catalyst by X-ray spectroscopy before and after catalysist+
}

\author{
Rafael Schiwon, ${ }^{a}$ Katharina Klingan, ${ }^{b}$ Holger Dau ${ }^{\mathrm{b}}$ and Christian Limberg* ${ }^{{ }^{a}}$
}

\begin{abstract}
Modification of the Co-oxo cores of cobalt-polyoxometalate water oxidation catalysts is detectable by $\mathrm{X}$-ray absorption spectroscopy (XAS) as demonstrated by comparison of $\mathrm{Na}_{10}\left[\mathrm{Co}_{4}\left(\mathrm{H}_{2} \mathrm{O}\right)_{2}\left(\mathrm{PW}_{9} \mathrm{O}_{34}\right)_{2}\right]$ (1) and $\mathrm{Na}_{17}\left[\left(\left(\mathrm{Co}\left(\mathrm{H}_{2} \mathrm{O}\right)\right) \mathrm{Co}_{2} \mathrm{PW}_{9} \mathrm{O}_{34}\right)_{2}\left(\mathrm{PW}_{6} \mathrm{O}_{26}\right)\right]$ (2). XAS reveals the integrity of 1 uncompromised by oxidant-driven water oxidation, which proceeds without formation of catalytic cobalt oxide.
\end{abstract}

Striving for new solar fuels, the water oxidation reaction is currently considered to be a bottleneck, hampering progress in the development of applicable technologies for the conversion of light into storable fuels. ${ }^{1}$ Intense research efforts are thus being pursued in order to develop both heterogeneous and molecular catalysts, which enable water oxidation at potentials close to the thermodynamic limit. A breakthrough has recently been achieved in the area of heterogeneous catalysis. Nocera and coworkers reported an in situ formed, self-healing Co-based catalyst (CoCat), which operates at moderate overpotentials as a water oxidation electrocatalyst. ${ }^{2,3}$ The CoCat is readily formed by electrodeposition from a buffered $\mathrm{Co}^{2+}$ solution as an amorphous film on the electrode surface; its atomic structure is characterized by cobalt oxide units composed of edge-sharing $\mathrm{CoO}_{6}$ octahedra. ${ }^{4}$ Also homogeneous WOCs are developing rapidly. ${ }^{1,5-9}$ The majority of the latter are based on (tailor-made) organic ligands which naturally represent the Achilles' heel of such systems. In this context the use of defective polyoxometalate (POM) derivatives as ligands is an interesting approach for the design of WOCs with enhanced stability, because oxidative ligand degradation is not possible. Therefore, the recent report ${ }^{10}$ that the purely inorganic $\mathrm{POM} \mathrm{Na} \mathrm{Na}_{10}\left[\mathrm{Co}_{4}\left(\mathrm{H}_{2} \mathrm{O}\right)_{2}\right.$ $\left.\left(\mathrm{PW}_{9} \mathrm{O}_{34}\right)_{2}\right]$, 1, based on earth-abundant cobalt represents an active WOC with $\left[\mathrm{Ru}(\mathrm{bpy})_{3}\right]\left(\mathrm{ClO}_{4}\right)_{3}$ (bpy $=$ tris $\left(2,2^{\prime}\right.$-bipyridyl $)$ ) as the oxidant

\footnotetext{
${ }^{a}$ Humboldt-Universität zu Berlin, Institut für Chemie, Brook-Taylor-Str. 2, 12489 Berlin, Germany. E-mail: christian.limberg@chemie.hu-berlin.de

${ }^{b}$ Freie Universität Berlin, FB Physik, Arnimallee 14, 14195 Berlin, Germany. E-mail: holger.dau@fu-berlin.de

$\dagger$ Dedicated to Prof. Dr Werner Uhl on the occasion of his 60th birthday. \$ Electronic supplementary information (ESI) available: Experimental section and details of the synthesis of 1, 2, $\left[\mathrm{Ru}(\mathrm{bpy})_{3}\right]\left(\mathrm{ClO}_{4}\right)_{3}$ and the spectroscopic details of the UV/Vis, EXAFS and XANES experiments. CCDC 943020. For ESI and crystallographic data in CIF or other electronic format see DOI: 10.1039/c3cc46629a
}

has received significant attention. ${ }^{11-13}$ To us this system seemed to be an interesting subject for X-ray absorption spectroscopy (XAS) studies as it may be viewed as a molecular and perhaps more defined version of Nocera's heterogeneous CoCat, which some of us have investigated structurally and electronically with the aid of X-ray absorption nearedge structure (XANES) and extended X-ray absorption fine-structure (EXAFS) spectroscopy. ${ }^{4,14}$ Recently it has been put into question that 1 is stable as such under turnover conditions. ${ }^{11,15}$ Therefore we decided to investigate the hydrolytic stability and possible catalyst degradation during catalysis by XAS. ${ }^{19}$

The synthesis of $\mathbf{1}$ has been performed according to a procedure established previously ${ }^{16}$ and its identity was confirmed by singlecrystal X-ray diffraction (XRD, Fig. S1 and Table S2, ESI $\ddagger$ ) and mass spectroscopy (Table S3 and Fig. S2-S8, ESI $\ddagger$ ) as well as by XANES and EXAFS. These structural methods were complemented by UV/Vis spectroscopy (Fig. S9-S19, ESI $¥$ ).

As there were conflicting reports on the solution stability of 1 even before catalysis, ${ }^{10,11,15}$ we have monitored its UV/Vis spectrum under various conditions. While $\mathbf{1}(1 \mathrm{mM})$ is indeed stable in pure water, addition of sodium phosphate $\left(\mathrm{NaP}_{\mathrm{i}}\right)$, used in the previous investigations ${ }^{10}$ to ensure a $\mathrm{pH}$ of $8(30 \mathrm{mM}$ for solutions being $3.2 \mu \mathrm{M} \mathrm{1})$, triggers a slow decrease of its main absorbance band at $580 \mathrm{~nm}$, thus indicating decomposition to some extent. Interestingly, the rate depends on the $\mathrm{NaP}_{\mathrm{i}}$ concentration: for a $30 \mathrm{mM} \mathrm{NaP}$ i solution a band decrease of $2 \%$ was observed within $1.5 \mathrm{~h}$ while it amounted to $3.5 \%$ in the case of $400 \mathrm{mM} \mathrm{NaP}$. However, very recent results ${ }^{20}$ suggest that such aging does not play a role in catalytic activity. Stability of the oxidant $\left[\mathrm{Ru}(\mathrm{bpy})_{3}\right]\left(\mathrm{ClO}_{4}\right)_{3}$ used has been investigated before, too. ${ }^{17}$ Albeit not the focus of our investigation, related results obtained by UV/Vis spectroscopy may be of interest and thus are reported herein. In contrast to the rather slow corrosion of $\mathbf{1}$ in aqueous solution, decomposition of $\left[\mathrm{Ru}(\mathrm{bpy})_{3}\right]^{3+}$ in a $30 \mathrm{mM}$ buffer of $\mathrm{NaP}_{\mathrm{i}}$ is more significant (Fig. S9, ESI $\$$ ). Monitoring the UV/Vis absorption maximum of $\left[\mathrm{Ru}(\mathrm{bpy})_{3}\right]^{3+}$ at $670 \mathrm{~nm}$ with time (Fig. S10, ESI ) suggests redox-degradation with a $t_{1 / 2}$ of $c a .75 \mathrm{~s}$. The product(s) showed a new band at $800 \mathrm{~nm}$.

The addition of a $3.2 \mu \mathrm{M}$ solution of 1 to a solution being $1.5 \mathrm{mM}$ in $\left[\mathrm{Ru}(\mathrm{bpy})_{3}\right]\left(\mathrm{ClO}_{4}\right)_{3}$ and $30 \mathrm{mM}$ in $\mathrm{NaP}_{\mathrm{i}}$ significantly accelerates the 
bleaching of the $670 \mathrm{~nm}$ band belonging to $\left[\mathrm{Ru}(\mathrm{bpy})_{3}\right]^{3+}$ (Fig. S11 and S12, ESI ), as expected for water oxidation catalyzed by $\mathbf{1}$, and indeed $\mathrm{O}_{2}$ evolution with a yield of $66.7 \%$ has been shown. ${ }^{10}$ Hence, under these conditions reduction of $\left[\mathrm{Ru}(\mathrm{bpy})_{3}\right]^{3+}$ to $\left[\mathrm{Ru}(\mathrm{bpy})_{3}\right]^{2+}$ is much faster than degradation.

For investigation of the atomic structure of the WOCs, Co K-edge XAS spectra of the following samples were collected: (a) microcrystalline powder of 1 , (b) $3.2 \mu \mathrm{M}$ of 1 , (c) $3.2 \mu \mathrm{M}$ of 1 with $1.5 \mathrm{mM}$ $\left[\mathrm{Ru}(\mathrm{bpy})_{3}\right]^{3+}$, (d) $1 \mathrm{mM}$ of 1 , (e) $1 \mathrm{mM}$ of 1 with $8 \mathrm{mM}\left[\mathrm{Ru}(\mathrm{bpy})_{3}\right]^{3+}$ (b-e, 1 in aqueous solutions being $30 \mathrm{mM}^{\text {in }} \mathrm{NaP}_{\mathrm{i}}, \mathrm{pH}$ 8). All samples were frozen in liquid nitrogen and spectra were collected at $20 \mathrm{~K}$. The oxidant-containing samples were not immediately frozen but after water oxidation catalysis.

XANES analysis was employed to investigate $\mathbf{1}$ in aqueous solution at the same low concentration $(3.2 \mu \mathrm{M})$ used previously for assessment of its catalytic performance. ${ }^{10}$ A clearly higher concentration of 1 $(1 \mathrm{mM})$ facilitated collection of high-quality EXAFS spectra. To verify the ability of XAS to detect structural changes in the cobalt oxo core of $\mathbf{1}$, in addition the known Co-POM Na $17\left[\left(\left(\mathrm{Co}\left(\mathrm{H}_{2} \mathrm{O}\right)\right) \mathrm{Co}_{2} \mathrm{PW}_{9} \mathrm{O}_{34}\right)_{2}\left(\mathrm{PW}_{6} \mathrm{O}_{26}\right)\right]$, 2, with a similar but somewhat different metal oxo core (ref. S5, ESI $\dagger$ ) was synthesized and, after verification of its structure by XRD, investigated by XAS in form of a microcrystalline powder.

The XANES spectra are shown in Fig. 1. Visual inspection immediately reveals that for $\mathbf{1}$ dissolved at low and high concentration $(3.2 \mu \mathrm{m}$ and $1 \mathrm{mM})$, the spectra recorded before and after the $\mathrm{Ru}^{\mathrm{III}}$-driven oxygen-evolving reaction (OER) are virtually identical. Moreover, these four solution spectra are highly similar to the spectrum of the microcrystalline powder of $\mathbf{1}$, but differ slightly from the spectrum of 2 (absence of a shoulder at $7730 \mathrm{eV}$ in 2). We also compared 1 to two conceivable products of hydrolytic decomposition or oxidative transformation: (I) $\left[\mathrm{Co}\left(\mathrm{H}_{2} \mathrm{O}\right)_{6}\right]^{2+}$ and (II) the CoCat. The XANES spectra of I and II differ pronouncedly from

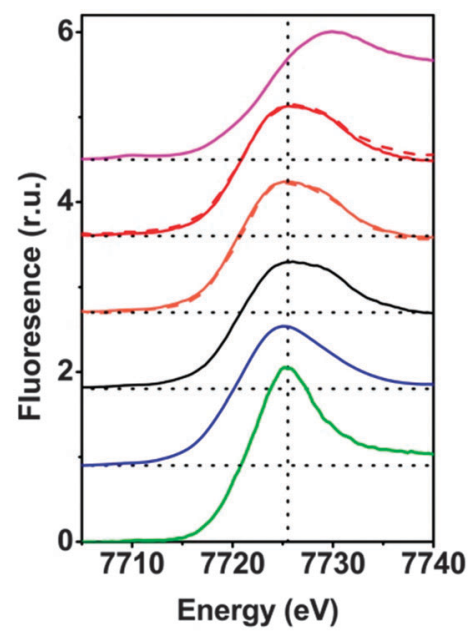

Fig. 1 Cobalt K-edge XANES spectra. (i) Heterogeneous Co'l'-oxide catalyst (CoCat, magenta), (ii) $3.2 \mu \mathrm{M}$ of 1 with $1.5 \mathrm{mM}\left[\mathrm{Ru}(\mathrm{bpy})_{3}\right]^{3+}$ (red dashed line), (iii) $1 \mathrm{mM}$ of 1 with $8 \mathrm{mM}\left[\mathrm{Ru}(\mathrm{bpy})_{3}\right]^{3+}$ (red), (iv) $3.2 \mu \mathrm{M}$ of 1 (orange dashed line), (v) $1 \mathrm{mM}$ of 1 (orange); (vi) microcrystalline powder of 1 (black), (vii) microcrystalline powder of 2 (blue), (viii) [Co" $\left.\left(\mathrm{H}_{2} \mathrm{O}\right)_{6}\right]\left(\mathrm{NO}_{3}\right)_{2}$ in aqueous solution (green). In (ii-v), 1 and $\left[\mathrm{Ru}(\mathrm{bpy})_{3}\right]^{3+}$ were mixed in an aqueous phosphate buffer (30 $\mathrm{mM} \mathrm{NaP}$ ). All samples were frozen in liquid nitrogen before XAS data collection (at $20 \mathrm{~K}$ ). We note that the spectra (ii)-(v) are virtually identical and highly similar to (vi). the spectra of 1 . In conclusion, already the visual comparison of the XANES suggests that hydrolytic or oxidative transformation of $\mathbf{1}$ does not take place to an extent detectable by XANES.

The K-edge positions on the energy axis are influenced by the oxidation state of the respective transition metal. An empirical relationship between the integral edge position ${ }^{18}$ and the oxidation state facilitates estimation of cobalt ion oxidation states of cobalt oxides and related Co-compounds. ${ }^{14}$ The edge positions of 1 before dissolution, after dissolution and after catalysis are, within the error limit, identical (Table S5, ESI $\$$ ) and confirm a Co oxidation state of +2 , as in the crystallographically characterized form of $\mathbf{1}$. The estimated edge position of CoCat is close to +3 , as reported before; ${ }^{4}$ the oxidation state of the $\mathrm{Co}^{2+}$ hexaaquo complex was estimated to be $2.0 \pm 0.1$ as expected. Thus we conclude that the oxidation state of $\mathbf{1}$ is conserved upon dissolution of the microcrystalline powder and upon water oxidation using $\left[\mathrm{Ru}(\mathrm{bpy})_{3}\right]^{3+}$. We note that the latter finding does not exclude that higher cobalt oxidation states are formed during water oxidation because the herein investigated samples were frozen at a point where water oxidation had come to an end because of exhaustion of the $\left[\mathrm{Ru}(\mathrm{bpy})_{3}\right]^{3+}$ oxidant.

Whereas the XANES region is sensitive mostly to oxidation states and the coordination geometry in the first coordination sphere, the EXAFS region of the spectrum can provide specific structural information on the first, second, third and higher coordination spheres. Fig. 2 compares Fourier-transformed (FT) EXAFS spectra; the $x$-axis indicates the reduced distance between the X-ray-absorbing Co ion and 'backscattering atoms' of the first and higher coordination spheres. The indicated reduced distances are by about $0.4 \AA$ shorter than the real distances obtained by EXAFS simulations and presented in Table 1 as well as Table S4 (ESI + ). The five prevalent FT-peaks (a-e) of the POM samples are assigned to atom pairs as shown in Fig. 3.

Visual comparison of the EXAFS spectra (Fig. 2) as well as the structural parameters determined by EXAFS simulation (Table 1)

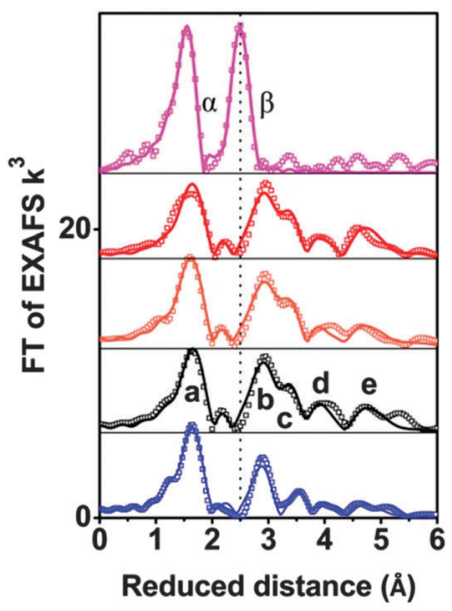

Fig. 2 Fourier-transformed EXAFS spectra of CoCat (deposited in $\mathrm{KP}_{\mathrm{i}}$, magenta), 2 powder (blue), 1 powder (black), $1 \mathrm{mM} 1$ in $30 \mathrm{mM} \mathrm{NaP}$ (orange); and $1 \mathrm{mM} 1$ and $8 \mathrm{mM}\left[\mathrm{Ru}(\mathrm{bpy})_{3}\right]^{3+}$ in $30 \mathrm{mM} \mathrm{NaP}$ (red) are shown. Experimental data are indicated by symbols and EXAFS simulations (parameters given in Table 1) are shown as lines. Note that the distance on the $x$-axis is reduced by $0.3-0.4 \AA$ relative to the real distance. Peaks (a-e) as well as $\alpha$ and $\beta$ correspond to distance vectors shown in Fig. 2. 
Table 1 Parameters of the EXAFS simulations for the atom pairs of the first (Co-O) and second (Co-Co) coordination spheres of cobalt. $\mathrm{N}_{\mathrm{i}}$, EXAFS coordination number (atoms per X-ray absorbing Co atom); $R_{\mathrm{i}}$, atomatom distance; $\sigma_{\mathrm{i}}$, Debye-Waller parameter. The parameter errors correspond to the $68 \%$ confidence interval. The Debye parameters labeled by * have been fixed for reproduction of the known coordination numbers of 1 in microcrystalline form. For the complete set of simulation parameters for all considered coordination shells, see Table S4 (ESI)

\begin{tabular}{lllll}
\hline & Co-O & & \\
\cline { 2 - 5 } Sample & $N_{\mathrm{O}}$ & $R_{\mathrm{O}}(\AA)$ & $\sigma_{\mathrm{O}}(\AA)$ & $R_{\mathrm{f}}$ \\
\hline CoCat & $6.0 \pm 0.3$ & $1.89 \pm 0.01$ & $0.064 \pm 0.002$ & 17 \\
$\mathbf{1},\left[\mathrm{Ru}(\mathrm{bpy})_{3}\right]^{3+}$ & $5.9 \pm 0.8$ & $2.05 \pm 0.01$ & $0.081^{*}$ & 20 \\
$\mathbf{1}(\mathrm{l})$ & $6.7 \pm 0.8$ & $2.04 \pm 0.01$ & $0.081^{*}$ & 20 \\
$\mathbf{1}(\mathrm{s})$ & $6.0 \pm 0.8$ & $2.05 \pm 0.01$ & $0.081^{*}$ & 20 \\
$\mathbf{2}(\mathrm{s})$ & $6.5 \pm 0.4$ & $2.05 \pm 0.01$ & $0.081^{*}$ & 22 \\
\hline & & & & \\
& & & & $R_{\mathrm{f}}$ \\
Sample & $N_{\mathrm{Co}}$ & $\mathrm{R}_{\mathrm{Co}}(\AA)$ & $\sigma_{\mathrm{Co}}(\AA)$ & 17 \\
\hline CoCat & $4.3 \pm 0.3$ & $2.81 \pm 0.01$ & $0.068 \pm 0.002$ & 20 \\
$\mathbf{1},\left[\mathrm{Ru}(\mathrm{bpy})_{3}\right]^{3+}$ & $2.4 \pm 0.4$ & $3.19 \pm 0.01$ & $0.044^{*}$ & 20 \\
$\mathbf{1}(\mathrm{l})$ & $2.5 \pm 0.4$ & $3.19 \pm 0.01$ & $0.044^{*}$ & 22 \\
$\mathbf{1}(\mathrm{s})$ & $2.5 \pm 0.4$ & $3.19 \pm 0.01$ & $0.044^{*}$ & \\
$\mathbf{2}(\mathrm{s})$ & $1.5 \pm 0.2$ & $3.18 \pm 0.01$ & $0.044^{*}$ & \\
\hline
\end{tabular}
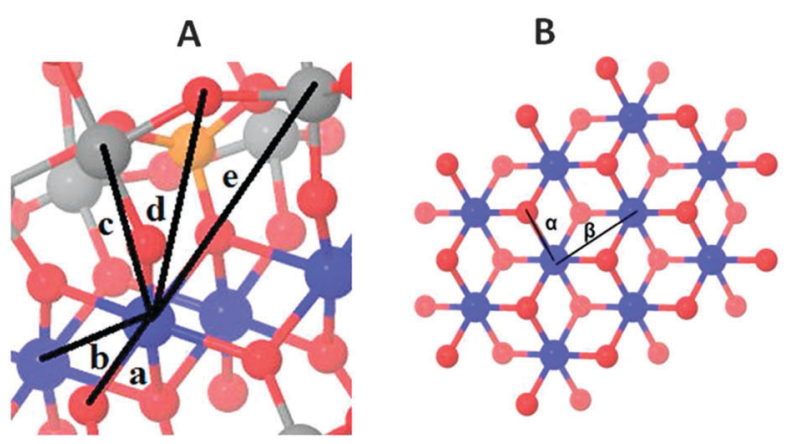

Fig. 3 Co oxo core and distance vectors in 1 (A) and the Co-based heterogenous catalysts (CoCat, B). The distances resolved by EXAFS analysis between the $X$-ray absorbing Co ion and neighbouring atoms are shown for $\mathbf{1}$ (a-e in panel A) and the CoCat ( $\alpha$ and $\beta$ in panel B) (Co blue, O red, $\mathrm{P}$ orange, and $\mathrm{W}$ grey).

reveal that neither dissolving $\mathbf{1}$ in aqueous buffer nor oxidant exposure and water oxidation catalysis causes structural modification. The comparison with CoCat reveals that the Co-Co peak distance of $2.81 \AA$ typical of edge-sharing octahedra in CoCat (FT peak labeled as $\beta$ ) is fully absent for $\mathbf{1}$, before and after catalysis of water oxidation.

Comparison of $\mathbf{1}$ and $\mathbf{2}$ illustrates the high sensitivity of the EXAFS spectra to structural changes within Co oxo cores: the two POMs only differ in the number of Co atoms interconnected by oxobridges and sandwiched between oxo tungstates (four Co in 1 versus three Co in 2, see Fig. S20, ESI ). Consequently the number of Co-Co vectors per X-ray absorbing Co ion is 2.5 in 1 and 1.5 in 2. The EXAFS simulations reproduce the predicted difference in the coordination number perfectly well ( $N_{\mathrm{Co}-\mathrm{Co}}$ of 1.5 in 2 vs. 2.5 in 1, Table 1). We conclude that for $\mathrm{CO}_{4}$-POM 1 even the loss of a single Co ion would be detectable by qualitative comparison of EXAFS spectra (i.e., visual comparison of Fourier-transformed spectra) and quantitative analysis (that is, determination of structural parameters by curve-fitting).
In conclusion, the EXAFS analysis corroborates the absence of hydrolytic or oxidative transformation of $\mathbf{1}$. Recently it was shown that electrocatalytic water oxidation in the presence of $\mathbf{1}$ involves its partial decomposition and release of $\mathrm{Co}^{2+}$ followed by deposition of a thin CoCat oxide film on the working electrode; not 1 but the amorphous Co oxide was suggested to be the WOC. ${ }^{11}$ Avoiding relatively harsh electrocatalytic conditions and using a chemical oxidant at neutral $\mathrm{pH}$, there are no indications of formation of a catalytically active Co oxide. We cannot exclude that, e.g., $5 \%$ of the Co ions are transformed into CoCat-type oxides. If these $5 \%$ of the Co ions were responsible for water oxidation catalysis, their TOF would exceed $2 \mathrm{~s}^{-1}$, though, whereas the TOF for the CoCat is clearly below $0.1 \mathrm{~s}^{-1}$. Thus it is highly unlikely that a minority fraction of Co ions present in oxide form could be responsible for WOC. A further recent proposal has been hydrolytic fragmentation of 1 into soluble species, ${ }^{15}$ which then perform the catalysis. If so, these fragments reassemble to give back $\mathbf{1}$ after catalysis, according to our results or would exhibit an extreme activity.

The herein presented evidence suggests that Co-POMs, which are composed exclusively of chemical elements of relatively high abundance, can be stable under catalytic conditions and thus are indeed promising WOCs.

This work has been pursued within the framework of the Berlin cluster of excellence on 'Unifying Concepts in Catalysis' (UniCat).

\section{Notes and references}

1 H. Dau, C. Limberg, T. Reier, M. Risch, S. Roggan and P. Strasser, ChemCatChem, 2010, 2, 724-761.

2 M. W. Kanan and D. G. Nocera, Science, 2008, 321, 1072-1075.

3 S. Y. Reece, J. A. Hamel, K. Sung, T. D. Jarvi, A. J. Esswein, J. J. H. Pijpers and D. G. Nocera, Science, 2011, 334, 645-648.

4 M. Risch, V. Khare, I. Zaharieva, L. Gerencser, P. Chernev and H. Dau, J. Am. Chem. Soc., 2009, 131, 6936-6937.

5 X. Sala, I. Romero, M. Rodríguez, L. Escriche and A. Llobet, Angew. Chem., Int. Ed., 2009, 48, 2842-2852.

6 R. Brimblecombe, G. C. Dismukes, G. F. Swiegers and L. Spiccia, Dalton Trans., 2009, 9374-9384.

7 M. Yagi, A. Syouji, S. Yamada, M. Komi, H. Yamazaki and S. Tajima, Photochem. Photobiol. Sci., 2009, 8, 139-147.

8 C. W. Cady, R. H. Crabtree and G. W. Brudvig, Coord. Chem. Rev., 2008, 252, 444-455.

9 M. R. g. I. Romero, C. Sens, J. Mola, M. R. Kollipara, L. Francás, E. Mas-Marza, L. Escriche and A. Llobet, Inorg. Chem., 2008, 47, 1824.

10 Q. Yin, J. M. Tan, C. Besson, Y. V. Geletii, D. G. Musaev, A. E. Kuznetsov, Z. Luo, K. I. Hardcastle and C. L. Hill, Science, 2010, 328, 342-345.

11 J. J. Stracke and R. G. Finke, J. Am. Chem. Soc., 2011, 133, 14872.

12 D. Lieb, A. Zahl, E. F. Wilson, C. Streb, L. C. Nye, K. Meyer and I. Ivanović-Burmazović, Inorg. Chem., 2011, 50, 9053-9058.

13 C. A. Ohlin, S. J. Harley, J. G. McAlpin, R. K. Hocking, B. Q. Mercado, R. L. Johnson, E. M. Villa, M. K. Fidler, M. M. Olmstead, L. Spiccia, R. D. Britt and W. H. Casey, Chem.-Eur. J., 2011, 17, 4408.

14 M. Risch, K. Klingan, F. Ringleb, P. Chernev, I. Zaharieva, A. Fischer and H. Dau, ChemSusChem, 2012, 5, 542-549.

15 M. Natali, S. Berardi, A. Sartorel, M. Bonchio, S. Campagna and F. Scandola, Chem. Commun., 2012, 48, 8808-8810.

16 R. G. Finke, M. W. Droege and P. J. Domaille, Inorg. Chem., 1987, 26, 3886-3896.

17 C. Creutz, H. A. Schwarz and N. Sutin, J. Am. Chem. Soc., 1984, 106, 3036-3037.

18 H. Dau, P. Liebisch and M. Haumann, Anal. Bioanal. Chem., 2003, 376, $562-583$.

19 For XAS on POM WOC also see: S. Piccinin, A. Sartorel, G. Aquilanti, A. Goldoni, M. Bonchio and S. Fabris, Proc. Natl. Acad. Sci. U. S. A., 2013, 110, 4917.

20 J. W. Vickers, H. Lv, J. M. Sumliner, G. Zhu, Z. Luo, D. G. Musaev, Y. V. Geletii and C. L. Hill, J. Am. Chem. Soc., 2013, 135, 14110-14118. 